\title{
Non-Invasive Moisture Detection for the Preservation of Cultural Heritage
}

\author{
Pier Matteo Barone ${ }^{1, *,+}+$ (i) and Carlotta Ferrara ${ }^{2,+}$ \\ 1 Archaeology and Classics Program, American University of Rome, Via Pietro Roselli 4, I-00153 Rome, Italy \\ 2 Research Centre for Forestry and Wood, Council for Agricultural Research and Economics (CREA), \\ Viale S. Margherita 80, I-52100 Arezzo, Italy; carlotta.ferrara@crea.gov.it \\ * Correspondence: p.barone@aur.edu \\ + These authors contributed equally to this work.
}

Received: 23 July 2018; Accepted: 8 August 2018; Published: 10 August 2018

\begin{abstract}
Moisture damage is the most critical issue regarding the preservation and integrity of cultural heritage sites. The electromagnetic (EM) sensitivity to the presence of moisture, in both soils and structural materials, is a well-known phenomenon. Thereby, studying the EM response to the presence of moisture, in order to prevent the damages done to sites of cultural heritage, is a well-established method. This paper will discuss the ability of a geophysical non-destructive technique (NDT), present in a Ground Penetrating Radar (GPR) system, to investigate a very precious building in Rome that is affected by a moisture problem (the Turkish Room at Villa Medici). This geophysical instrument is able to locate and estimate the extent of water ingression, which can aid in the development of restoration plans before permanent damage occurs. The main objective of this paper is to help restorers understand the related hazards, due to the presence of moisture in the wall structures, in real-time and to rapidly and non-invasively develop strategies for the preservation of cultural heritage sites.
\end{abstract}

Keywords: NDT; GPR; moisture; cultural heritage; preservation; Rome

\section{Introduction}

Moisture detection is one of the most relevant issues within Hydrogeophysics. Ground Penetrating Radar (GPR), in particular, can accurately assess the level of moisture in the subsoil. This type of geophysical non-destructive technique (NDT) can be used to accurately determine the moisture content below the earth's surface [1]. This electromagnetic (EM) technique can be used to estimate material parameters and to particularly obtain valuable information about the presence of moisture in an investigated medium. Moreover, this novel approach toward data analysis uses the acquired amplitude attribute information of the GPR signal with a standard, common-offset, and ground-coupled antenna configuration $[2,3]$. Under these conditions, where the antenna offsets are small, the direct GPR signal consists of a complex combination of the air and ground waves and carries information about the physical properties of the surrounding material. This is because the amplitude, shape, and duration of the signal change acts as a function of the EM properties of the soil [4,5].

The main results are as follows: (i) a systematic change in the amplitude and duration of early ground-coupled GPR signals is induced by spatial variations in the shallow soil's dielectric properties which, in this case, depend only on the distribution of water content in the subsurface medium; (ii) this new approach towards GPR data analysis is highly suitable for creating detailed maps of variations in the electric permittivity of the shallow subsurface (e.g., water content); (iii) the evaluation of the shallow soil's dielectric properties using this novel technique, instead of more traditionally 
configured radar systems, could represent a practical way to rapidly characterize materials at high spatial resolutions [1-5].

Several controlled experiments, numerical simulations, and "real-life" applications have been conducted to study the effects of EM parameter variations on antenna-material coupling. However, this approach toward evaluating variations in the shallow dielectric permittivity and conductivity (i.e., the presence of moisture) in a soil is more reliable and consistent than other methods [6-15].

Given the recent advancements in commercial geophysical systems, researchers are now exploring new spatial and temporal monitoring techniques which are capable of providing valuable information regarding the soil water content at the intermediate scales. The estimation of water content in this scale range is important in many hydrological processes, such as water infiltration, percolation, runoff, and evapotranspiration, that affect the investigated medium [16-18].

GPR has gained popularity in engineering and Cultural Heritage Preservation sectors, in particular, thanks to its applicability regarding water content estimation, damage evaluation, long-term masonry changes, restoration management, and location of cracks [3,4].

Herein, the acquired data is part of a broader study to plan a proper and more elaborate restoration of a precious building in the city-center of Rome. The aim of this study is to assess the capacity of surface GPR techniques to non-invasively monitor the internal moisture dynamics in a cultural heritage site. In particular, the novelty of this paper is the possibility to apply the real-time characteristics of the GPR methodology by acquiring the data and, at the same time, communicate the damages to the restorers for their immediate operations. Here, we would like to propose a different use of the GPR in a very specific situation within a limited time of intervention for both the GPR acquisition and the architectonic restoration. The novelty is exactly this "immediate" use of the GPR results for the restorations within the same morning of the operations.

\section{Materials and Methods}

The area under investigation was the Turkish Room at the Villa Medici situated on Pincio Hill in Rome, Italy. This hill does not belong to the seven major Roman hills because it is outside the pomoerium, which is the sacred wall of antique Rome. Beautiful ornamental facades, elaborate entrance gates, gardens replete with fantastic water displays, and antique statues once formed the stage for the grand theatrical entertainments of the Villa. The Villa Medici, founded by Ferdinando I $\mathrm{de}^{\prime}$ Medici—-the Grand Duke of Tuscany—and presently a property of the French State, has housed the French Academy in Rome since 1803 [19].

The Turkish Room, one the most picturesque areas of the building, which is situated in a tower, is an unusual boudoir with neo-Moorish decorations and has frescos overlooking Rome. It was designed in 1833 by Horace Vernet, then the Director of the French Academy, who had been inspired by a sojourn in Algiers at the time of the French conquest. Between 1961 and 1967, Balthus, then the head of the Academy, carried out a vast restoration campaign of the palace and its gardens and provided them with modern equipment. Recently, this room has been under heavy restoration due to damage, related to the presence of humidity, in the walls containing the detached portions of the frescos and decorations (Figure 1) [20]. 


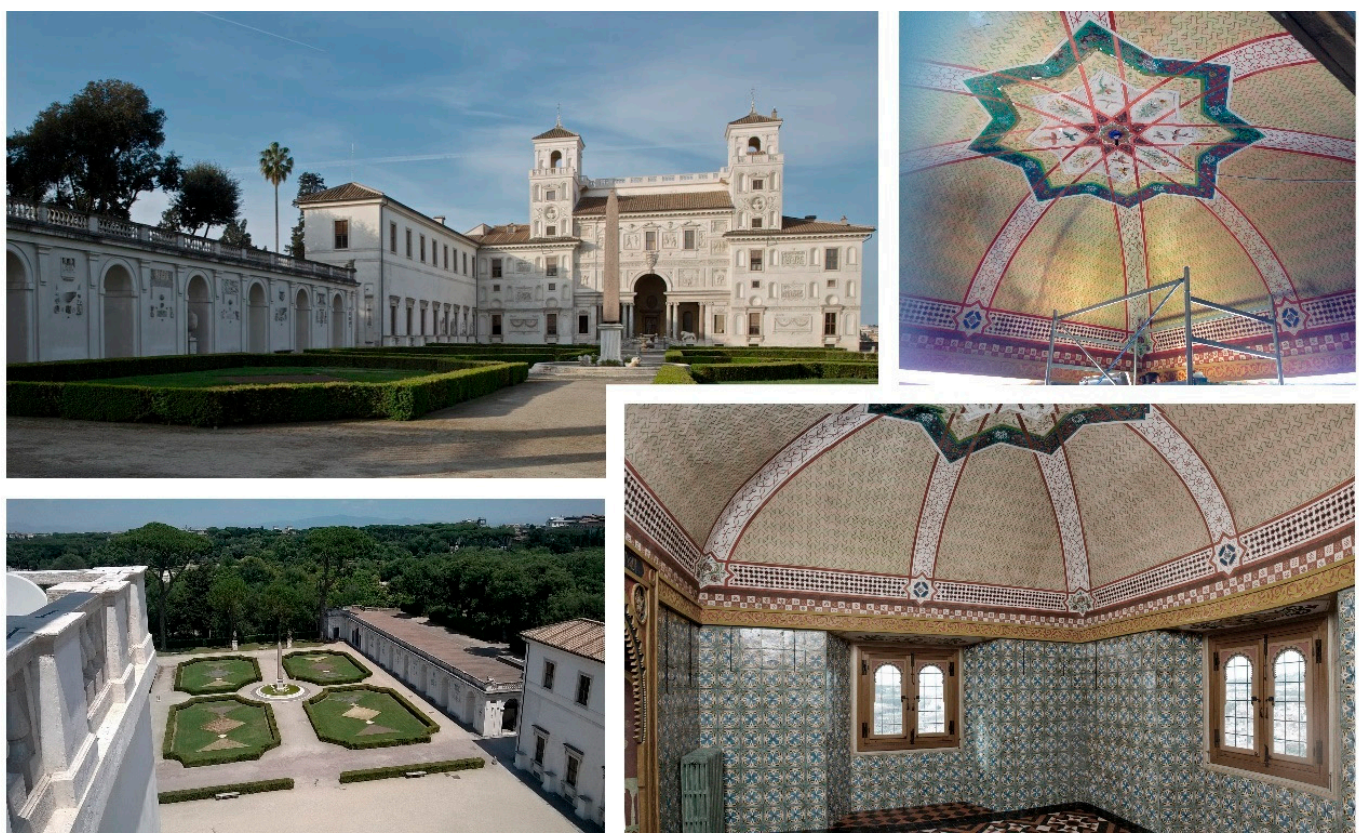

Figure 1. Villa Medici (left) and the Turkish Room (right). Note the damaged vault of the Turkish Room (top right).

The involved GPR instrument was the bistatic FINDAR (Sensors \& Software, Inc. Mississauga, ON, Canada) system equipped with a $500 \mathrm{MHz}$ antenna. Two one-way grids of $5 \times 5 \mathrm{~m}$ (one X-oriented, one Y-oriented), with a distance of $0.1 \mathrm{~m}$ among profiles, were acquired on the terrace above the Turkish Room's ceiling (Figure 2). No other processing was required beyond the standard one (Automatic Gain Control—a method of overcoming unwanted clutter echoes, DeWOW-removing the low-frequency component, the so-called "wow," of every trace, and the Average Envelope Amplitude of the signal) [21]. This is due to the aim of this paper: real-time acquisition, results, and operations. The signal penetration velocity was calculated using the hyperbola calibration and verified using the actual measurements of the exposed masonry, which was $0.12 \mathrm{~m} / \mathrm{ns}$.
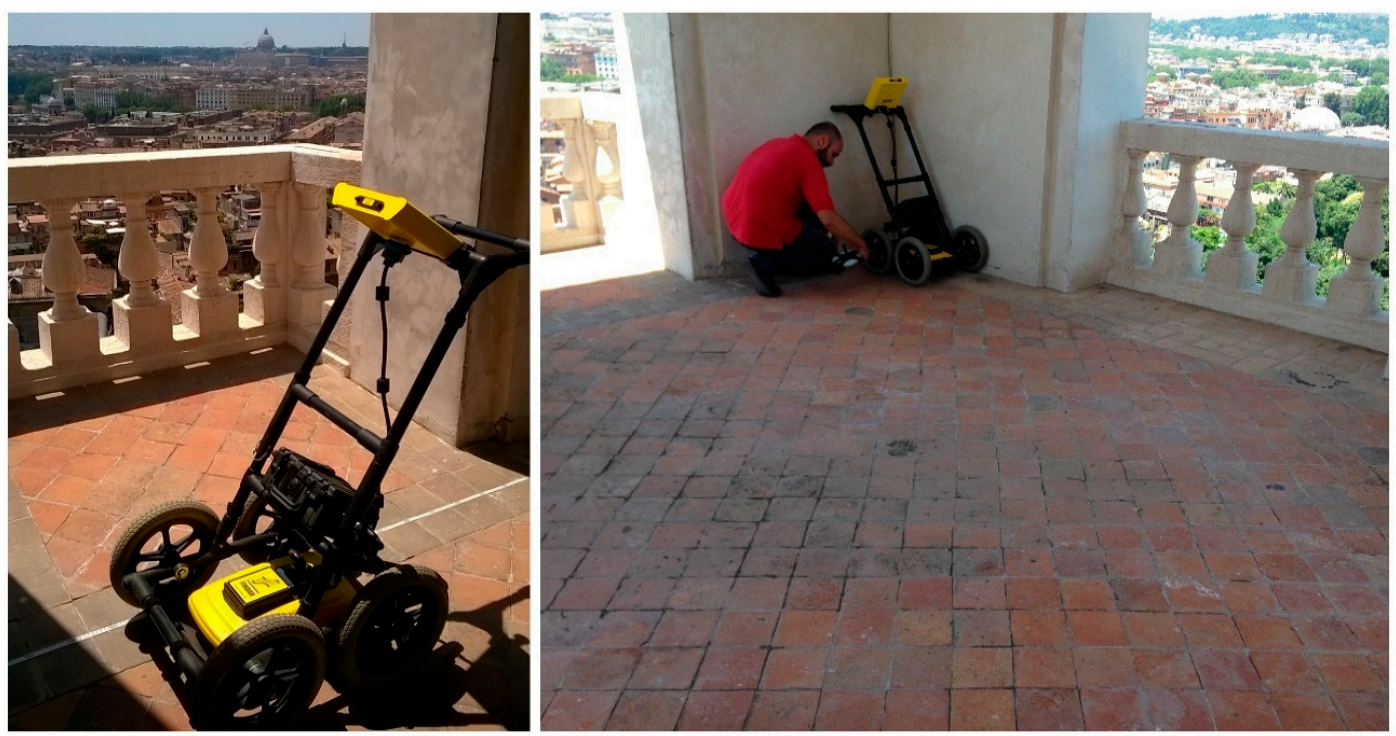

Figure 2. The Ground Penetrating Radar (GPR) equipment involved in the investigations (left) and the area of acquisition on the terrace above the Turkish Room's ceiling (right). 


\section{Results and Discussion}

Thanks to its high sensitivity to moisture, GPR investigation was necessary to localize the possible presence of moisture inside the ceiling of the room and to understand the level of structural damage entailing the presence of humidity. This was necessary to plan a proper and focused restoration plan of the Turkish Room vault.

Figure 3 shows a radargram collected almost in the middle of the vault below with a direction facing North-South. It is possible to clearly see the inner structure of the ceiling. The thickness and the geometry of the vault are particularly detectable due to the contrast between the architectonic structure and the air. Moreover, the composition of both the terrace pavement and the ceiling filling is visible-first, an almost-homogenous layer of bricks is present above with a thickness of about $0.5 \mathrm{~m}$, and different grouting materials below. In the middle of the radargram, there is an evident hyperbolic event at a depth of about $0.20 \mathrm{~m}$. This is due to the presence of an electrical cable, as the following depth-slices analysis will illustrate. It is worth noting that, because of its geometry, the vault thickness varies from a maximum of about $1.1 \mathrm{~m}$ to a minimum of about $0.70 \mathrm{~m}$.

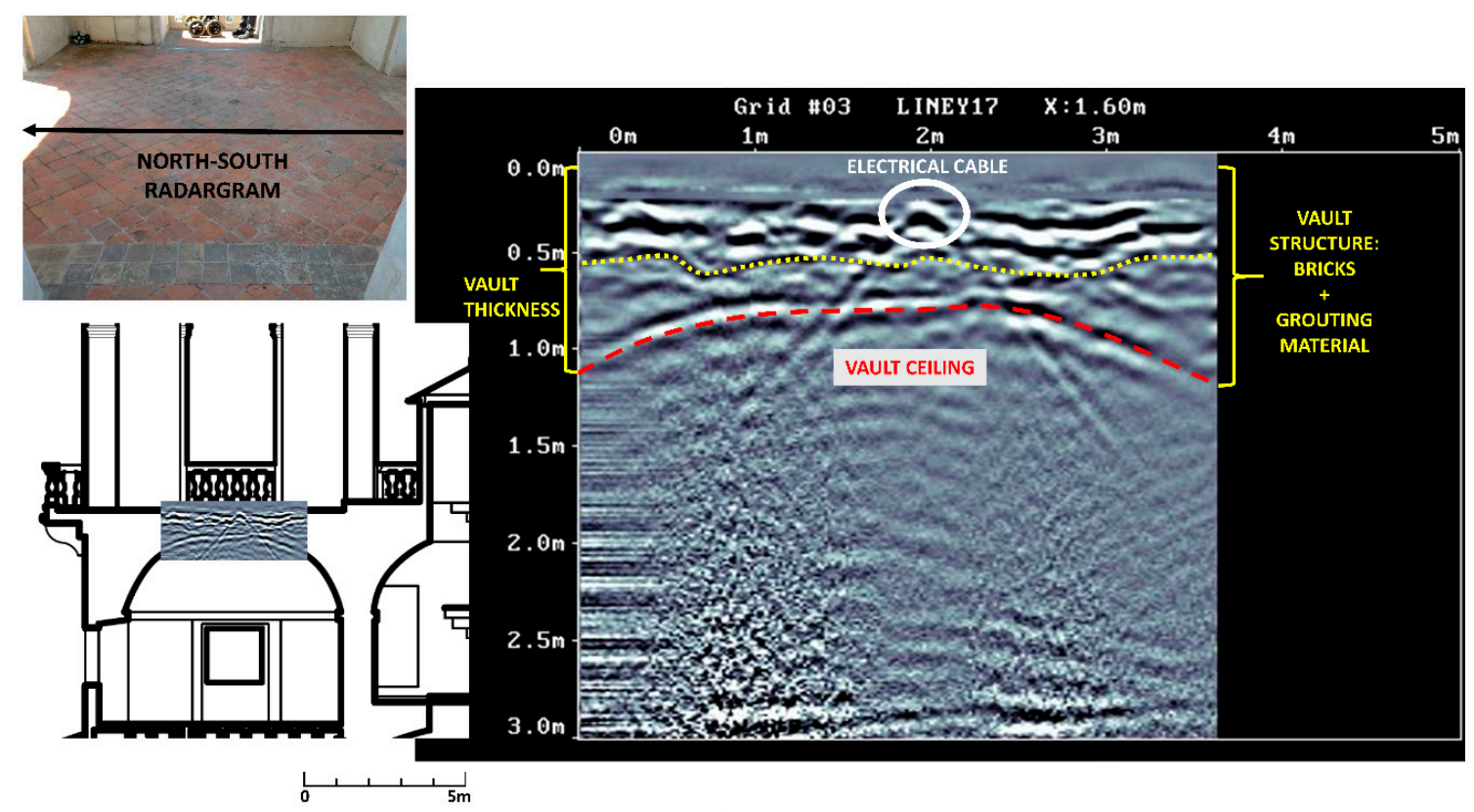

Figure 3. The radargram, which was acquired North-South in the middle of the vault below, clearly displays the inner structure of the terrace pavement and the vault ceiling-from the top, an initial brick layer and a second layer of grouting material. Note that the central hyperbolic event is probably due to an electrical cable. At the bottom left, there is an overlap of the architectonical section and the acquired radargram.

The depth-slices highlight the different kinds of targets (Figure 4). Starting from the near-surface one, two elongated anomalies are visible. These two evidences are possibly due to the presence of electrical cables at a depth of about $0.20 \mathrm{~m}$ inside the brick layer. The longest one is partially detected by the previous radargram, as shown in Figure 3. 

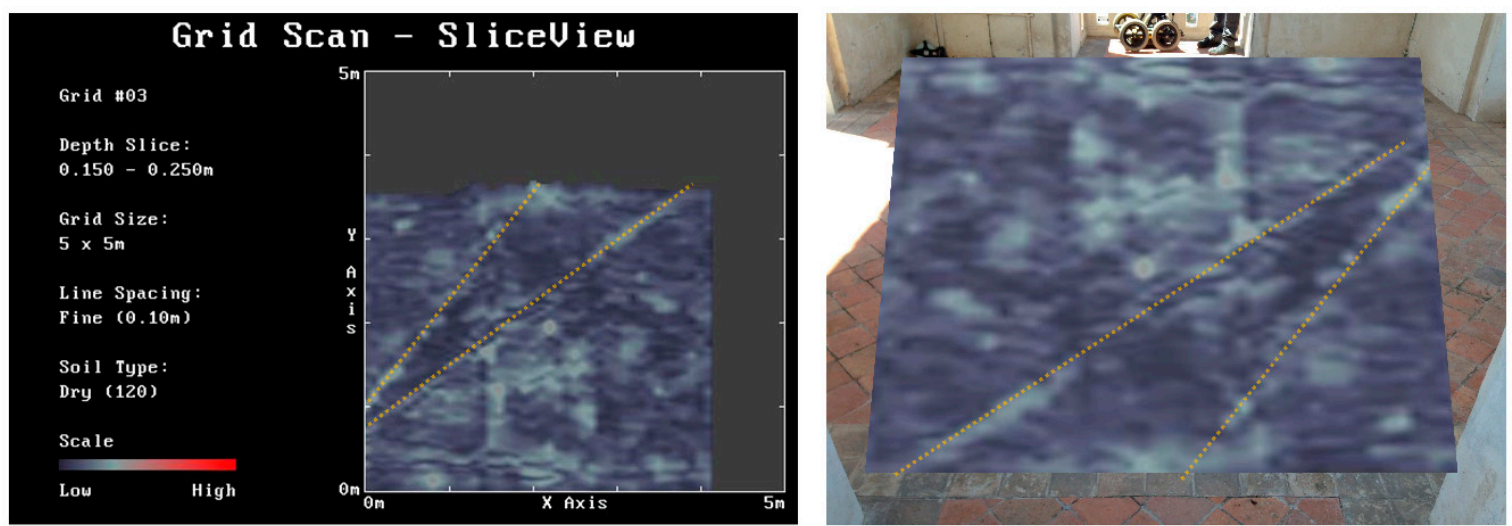

Figure 4. The figure on the left illustrates the elongated anomalies; the figure on the right locates the correct position below the terrace pavement.

In Figure 5, the results clearly highlight the presence of a strong anomaly related to the high presence of moisture in a specific part of the internal vault below. The intensity and definition of the anomaly allows us to understand the level of damage and to plan a focused restoration without entirely dismantling the ceiling of this precious room. The potential of such an NDT investigation, using the GPR, allows us to detect the presence and the dimensions of a moist layer inside this architectonical structure and (more importantly) to locate it in depth. In particular, there are two damaged areas-one larger than the other one-in a specific area of the vault (the southern side) at a depth of about $0.85 \mathrm{~m}$. Due to the lateral position and the depth of both the anomalies, it is possible to identify the humidity present at few centimeters behind the frescos of the vault below. In Figure 5, to the right, their position is indicated; the restoration started exactly from that portion of the room's ceiling.

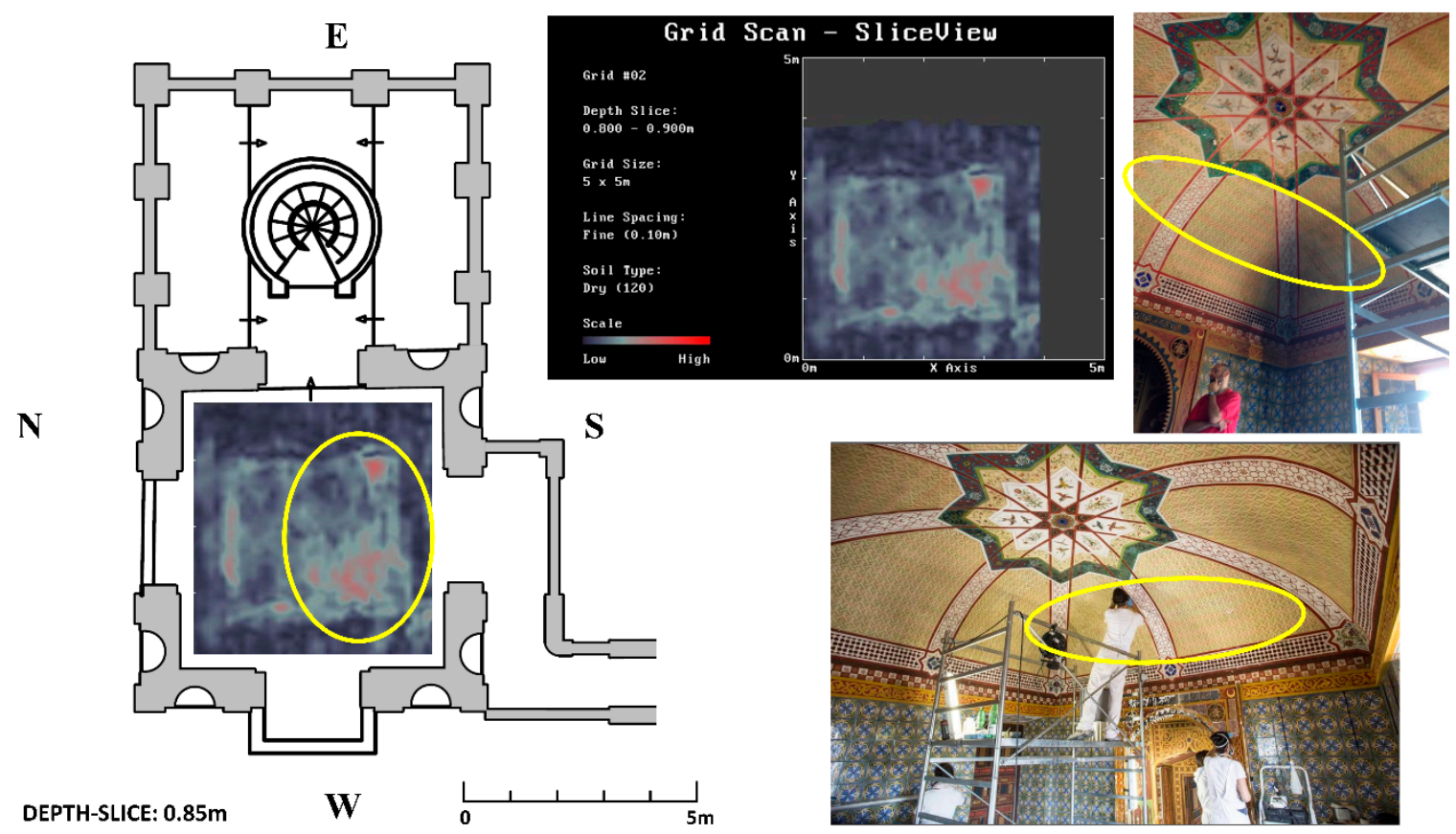

Figure 5. This figure illustrates the depth-slice at $0.85 \mathrm{~m}$ circa with the two anomalies caused due to moisture damage (left). The localization of these anomalies, inside the vault, helped the restorers to precisely plan the repair interventions (right). 
Finally, Figure 6 confirms the moisture presence, thanks to both the "time-stretched signal" and "ringing" effects. When GPR data are acquired using a fixed-offset, ground-coupled GPR antenna configuration, the dielectric permittivity affects both the amplitude and duration of the GPR signal; therefore, higher amplitudes and shorter wavelets are associated with lower permittivity $[5,7,8]$. The ringing anomalies in the radargrams with very low EM signal amplitudes-due to high attenuation, poor antenna coupling, and temporal stretching - can be analyzed in order to estimate the physical properties of near-surface materials in archaeological as well as cultural heritage sites [4,8,22]. Note that the signal amplitude is affected by variations in the EM parameters and particularly by permittivity changes. Hence, it is also possible to determine the medium's volumetric water content using an appropriate petrophysical relationship [16,18,23].

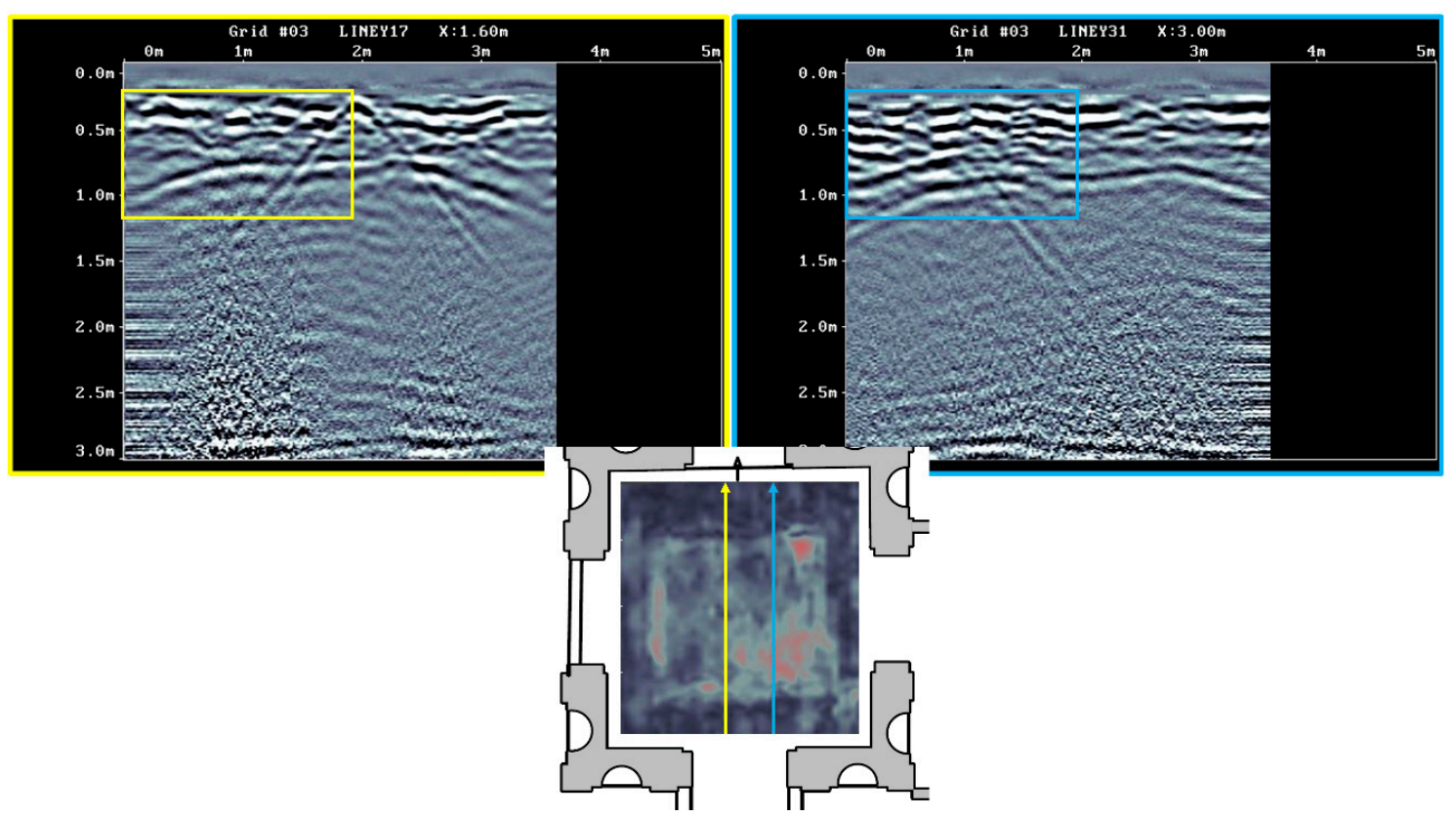

Figure 6. This figure compares two radargrams acquired in different positions (see the depth-slice map below) - a radargram without the anomaly due to humidity (left, in yellow) and a radargram with the anomaly (right, light blue). Note that in the light-blue rectangular area both the "time-stretched signal" and "ringing" effects are highlighted, but they are not visible in the yellow rectangle.

\section{Conclusions}

The results highlighted in this paper demonstrate the ability of an NDT, such as the GPR, to locate and estimate the extent of water ingression in order to develop restoration plans at the same time of the GPR investigations before permanent damage occurs. Rapidly and non-invasively, the GPR acquisition allows for the restoration managers to immediately develop strategies for the preservation of such a precious cultural heritage site. The restorers, right after the presentation of the GPR results, found the damaged areas behind the frescos and began to re-establish the original condition of the vault by removing the excess moisture in the area as displayed by the GPR investigations.

Author Contributions: Conceptualization, P.M.B. and C.F.; Data curation, P.M.B. and C.F.; Formal analysis, P.M.B. and C.F.; Funding acquisition, C.F.; Investigation, P.M.B. and C.F.; Methodology, P.M.B. and C.F.; Project administration, P.M.B. and C.F.; Resources, P.M.B. and C.F.; Supervision, P.M.B. and C.F.; Validation, P.M.B. and C.F.; Visualization, P.M.B. and C.F.; Writing—original draft, P.M.B. and C.F.; Writing-review and editing, P.M.B. and C.F.

Funding: This research received no external funding.

Acknowledgments: The authors would like to thank Valeria Di Tullio and Emiliano Ricchi for their logistics support during the measurements. 
Conflicts of Interest: The authors declare no conflict of interest.

\section{References}

1. Lambot, S.; Binley, A.; Slob, E.; Hubbard, S. Ground Penetrating Radar in Hydrogeophysics. Vadose Zone J. 2008, 7, 137-139. [CrossRef]

2. Davis, J.L.; Annan, A.P. Ground-Penetrating Radar for High-Resolution Mapping of Soil and Rock Stratigraphy. Geophys. Prospect. 1989, 37, 531-551. [CrossRef]

3. Wai-Lok Lai, W.; Dérobert, X.; Annan, A.P. Review of Ground Penetrating Radar application in civil engineering: A 30-year journey from Locating and Testing to Imaging and Diagnosis. NDT E Int. 2017, 96, 58-78. [CrossRef]

4. Barone, P.M. Understanding Buried Anomalies: A Practical Guide to GPR; LAP-Lambert Academic Publishing: Saarbrücken, Germany, 2016; ISBN 978-3659935794.

5. Ferrara, C.; Barone, P.M.; Steelman, C.; Pettinelli, E.; Endres, A.L. Monitoring shallow soil water content under natural field conditions using the early-time GPR signal technique. Vadose Zone J. 2013, 12. [CrossRef]

6. Saintenoy, A.; Schneider, S.; Tucholka, P. Evaluating ground penetrating radar use for water infiltration monitoring. Vadose Zone J. 2008, 7, 207-214. [CrossRef]

7. Ferrara, C.; Comite, D.; Barone, P.M.; Lauro, S.E.; Mattei, E.; Vannaroni, G.; Galli, A.; Pettinelli, E. An Evaluation of the Early-Time GPR Amplitude Technique for Electrical Conductivity Monitoring. In Proceedings of the 7th International Workshop on Advanced Ground Penetrating Radar (IWAGPR), Nantes, France, 2-5 July 2013. [CrossRef]

8. Ferrara, C.; Barone, P.M. Detecting Moisture Damage in Archaeology and Cultural Heritage: A Brief Introduction. Int. J. Archaeol. 2015, 3, 57-61. [CrossRef]

9. Meyer, K.; Erdogmus, E.; Morcous, G.; Naughtin, M. Use of Ground Penetrating Radar for Accurate Concrete Thickness Measurements. In Proceedings of the Architectural Engineering Conference (AEI) 2008, Denver, CO, USA, 24-27 September 2008.

10. Sbartaï, Z.M.; Laurens, S.; Balayssac, J.-P.; Ballivy, G.; Arliguie, G. Effect of concrete moisture on radar signal amplitude. Materials 2006, 103, 419-426.

11. Klysz, G.; Balayssac, J.-P. Determination of volumetric water content of concrete using ground-penetrating radar. Cem. Concr. Res. 2007, 37, 1164-1171. [CrossRef]

12. Laurens, S.; Balayssac, J.-P.; Rhazi, J.; Arliguie, G. Influence of concrete relative humidity on the amplitude of Ground-Penetrating radar (GPR) signal. Mater. Struct. 2002, 35, 198-203. [CrossRef]

13. Hugenschmidt, J.; Loser, R. Detection of chlorides and moisture in concrete structures with ground penetrating radar. Mater. Struct. 2008, 41, 785-792. [CrossRef]

14. Maierhofer, C. Nondestructive Evaluation of Concrete Infrastructure with Ground Penetrating Radar. J. Mater. Civ. Eng. 2003, 15, 287-297. [CrossRef]

15. Agliata, R.; Bogaard, A.T.; Greco, R.; Mollo, L.; Slob, E.C.; Steele-Dunne, S.C. Non-invasive estimation of moisture content in tuff bricks by GPR. Constr. Build. Mater. 2018, 160, 698-706. [CrossRef]

16. Sbartaï, Z.M.; Laurens, S.; Rhazi, J.; Balayssac, J.-P. Nondestructive evaluation of concrete structures using geophysical methods: Correlation between electrical resistivity and radar measurements. J. Appl. Geophys. 2007, 62, 361-374. [CrossRef]

17. Sbartaï, M. Ground Penetrating Radar. In In Situ Assessment of Structural Timber; RILEM State of the Art Reports; Kasal, B., Tannert, T., Eds.; Springer: Dordrecht, The Netherlands, 2011; Volume 7. [CrossRef]

18. Ferrara, C.; Di Tullio, V.; Barone, P.M.; Mattei, E.; Lauro, S.E.; Proietti, N.; Capitani, D.; Pettinelli, E. Comparison of GPR and Unilateral NMR for water content measurements in a laboratory scale experiment. Near Surf. Geophys. 2013, 11. [CrossRef]

19. Napoleone, C. Villa Medici: Le delizie del cardinale. Antiquariato 2013, 381, 106-111.

20. Hochmann, M. (Ed.) Villa Medici: Il Sogno di un Cardinale; De Luca Editore: Roma, Italy, 1999; ISBN 13 9788880163244.

21. Annan, A.P. Ground Penetrating Radar Principles, Procedures and Applications; Sensors and Software: Mississauga, ON, Canada, 2004. 
22. Lourenco, P.; Luso, E.; Almeida, M. Defects and moisture problems in buildings from historical city centres: A case study in Portugal. Build. Environ. 2006, 41, 223-234. [CrossRef]

23. Steelman, C.M.; Endres, A.L. Comparison of petrophysical relationships for soil moisture estimation using GPR ground waves. Vadose Zone J. 2011, 10, 270-285. [CrossRef]

(C) 2018 by the authors. Licensee MDPI, Basel, Switzerland. This article is an open access article distributed under the terms and conditions of the Creative Commons Attribution (CC BY) license (http://creativecommons.org/licenses/by/4.0/). 